\begin{tabular}{|c|c|}
\hline Title & Carbon Nanotube Synthesis via the Cal ciothermic Reduction of Carbon Dioxide with Iron A dditives \\
\hline Author(s) & $\begin{array}{l}\text { Kikuchi, Tatsuy a; Ishida, Ryoma; Natsui, Shungo; Kumagai, Takehiko; Ogino, Isao; Sakaguchi, Norihito; Ueda, } \\
\text { Mikito; Suzuki, Ryosuke O. }\end{array}$ \\
\hline Citation & $\begin{array}{l}\text { ECS Solid State Letters, 4(9), M19-M22 } \\
\text { https://doi.org/10.1149/2.0031509ssl }\end{array}$ \\
\hline Issue Date & 2015 \\
\hline Doc URL & http:/hdl.handle.net/2115/59569 \\
\hline Rights & $\begin{array}{l}\text { () The Electrochemical Society, Inc. 2015. All rights reserved. Except as provided under U.S. copyright law, this work } \\
\text { may not be reproduced, resold, distributed, or modified without the express permission of The Electrochemical Society } \\
\text { (ECS). The archival version of this work was published in ECS Solid State Letters. }\end{array}$ \\
\hline Rights(URL) & http://creativecommons.org/icenses/by-nc-nd/4.0/ \\
\hline Type & article \\
\hline File Information & CNT.pdf \\
\hline
\end{tabular}

Instructions for use 


\title{
Carbon Nanotube Synthesis via the Calciothermic Reduction of Carbon Dioxide with Iron Additives
}

\author{
Tatsuya Kikuchi, ${ }^{\mathrm{z}}$ Ryoma Ishida, Shungo Natsui, Takehiko Kumagai, Isao Ogino, \\ Norihito Sakaguchi, Mikito Ueda," and Ryosuke O. Suzuki
}

Faculty of Engineering, Hokkaido University, Sapporo, Hokkaido, 060-8628, Japan

The novel fabrication of multi-walled carbon nanotube (MWCNT)/cementite $\left(\mathrm{Fe}_{3} \mathrm{C}\right)$ nanocomposites was demonstrated via the calciothermic reduction of carbon dioxide $\left(\mathrm{CO}_{2}\right)$ through electrolysis in molten $\mathrm{CaCl}_{2} / \mathrm{CaO}$ with iron additives at $1173 \mathrm{~K}$. In this technique, $\mathrm{CO}_{2}$ generated from a graphite anode is reduced to carbon with a metallic calcium reductant formed on a graphite cathode via electrolysis in molten salt. Calciothermic reduction without iron additives resulted in the formation of onion-like carbons (OLCs) with spherical graphite layers and thin graphite sheets. In contrast, MWCNT/Fe $3 \mathrm{C}$ nanocomposites and OLCs were successfully fabricated via calciothermic reduction with iron additives through their catalytic activities.

(c) The Author(s) 2015. Published by ECS. This is an open access article distributed under the terms of the Creative Commons Attribution Non-Commercial No Derivatives 4.0 License (CC BY-NC-ND, http://creativecommons.org/licenses/by-nc-nd/4.0/), which permits non-commercial reuse, distribution, and reproduction in any medium, provided the original work is not changed in any way and is properly cited. For permission for commercial reuse, please email: oa@electrochem.org. [DOI: 10.1149/2.0031509ssl] All rights reserved.

Manuscript submitted June 16, 2015; revised manuscript received July 6, 2015. Published July 15, 2015.

Calciothermic reduction with a metallic calcium reductant is a powerful electrochemical technique for the direct reduction of metal oxides. ${ }^{1-3}$ Various transition metals can be directly reduced from their oxides with metallic calcium because of its strong reducing ability. Therefore, calciothermic reduction for industrial applications had been widely investigated by many research groups to date, and metallic titanium, ${ }^{4-9}$ zirconium, ${ }^{10,11}$ hafnium, ${ }^{12}$ niobium, ${ }^{13-15}$ tantalum, ${ }^{16,17}$ nickel, ${ }^{18}$ uranium, ${ }^{19}$ and their alloys ${ }^{20-27}$ can be successfully obtained via calciothermic reduction and advanced techniques. ${ }^{28,29}$

Although carbon dioxide $\left(\mathrm{CO}_{2}\right)$ is an extremely stable chemical species in our environment, the chemical decomposition of $\mathrm{CO}_{2}$ is an important technology for global environmental issues. ${ }^{30-32}$ In a previous investigation, the authors demonstrated a novel $\mathrm{CO}_{2}$ reduction technique via calciothermic reduction using molten salt electrolysis. ${ }^{33,34}$ In this process, $\mathrm{CO}_{2}$ was reduced to carbon and oxygen gas with a metallic calcium reductant formed by electrolysis in a calcium chloride molten salt containing calcium oxide at high temperatures. Rapid decomposition of $\mathrm{CO}_{2}$ could be successfully achieved by using metallic calcium. ${ }^{33}$ Notably, the reduced carbon products contained tube-like graphite with iron nanoparticles, which is similar to typical carbon nanotubes (CNTs). It could be that the origin of these iron nanoparticles was from a stainless steel pipe for the $\mathrm{CO}_{2}$ gas flow. The nanotubes grew on the contaminated iron particles, which acted as catalysts, but the details remained unclear. Therefore, electrolysis in molten salt with and without iron additives must be investigated for the understanding of nanotube formation.

In the present investigation, the authors investigated the reduction behavior of $\mathrm{CO}_{2}$ via calciothermic reduction in calcium chloride molten salt containing calcium oxide with and without iron additives. In this electrolysis procedure, $\mathrm{CO}_{2}$ generated from the anode by molten salt electrolysis is reduced into carbon with a metallic calcium reductant formed on the cathode. The details of the carbon products obtained via calciothermic reduction were examined by highresolution electron microscopy. The authors found that the addition of the iron microparticles into the molten salt is an important technique to fabricate CNTs by the calciothermic reduction of $\mathrm{CO}_{2}$.

\section{Experimental}

Calcium chloride $\left(\mathrm{CaCl}_{2}, 600 \mathrm{~g}\right)$ as the molten salt, calcium oxide $(\mathrm{CaO}, 1.5 \mathrm{~g})$ as the electrolyte, and iron powder (Fe, $300 \mathrm{mesh}, 1.0 \mathrm{~g})$ as the additives were dried in a vacuum oven at $473 \mathrm{~K}$. After drying, these chemicals were placed in a magnesium oxide $(\mathrm{MgO})$ crucible. In

*Electrochemical Society Active Member.

${ }^{\text {z} E-m a i l: ~ k i k u @ e n g . h o k u d a i . a c . j p ~}$ the electrolysis with iron additives, iron powder added to the bottom of $\mathrm{MgO}$ crucible before electrolysis. The crucible was then set in a SUS316L stainless steel reaction chamber, and the chemicals were dehydrated at $873 \mathrm{~K}$ for more than $36 \mathrm{ks}$ under vacuum conditions. After dehydration, the reaction chamber was gradually heated up to $1173 \mathrm{~K}$ under an argon atmosphere $(101.3 \mathrm{kPa})$ to melt the salt and electrolyte. Two graphite rods (10 mm in diameter, IG-11, Toyo Tanso, Japan) to act as the anode and the cathode were immersed in the molten $\mathrm{CaCl}_{2} / \mathrm{CaO}$. The distance between the anode and cathode and immersion depth of each electrode were adjusted to $40 \mathrm{~mm}$ and 35 $\mathrm{mm}$, respectively. A constant voltage of $3.1 \mathrm{~V}$ was applied for $\mathrm{t}=8$ ks using a direct current power supply (PWR-400H, Kikusui, Japan) connected to a computer. The current was measured during constant voltage electrolysis.

After electrolysis, the anode and cathode were pulled up from the molten salt, and then, the reaction chamber was cooled to room temperature. After it was completely cool, the crucible was removed from the vessel and then washed with water to remove the solidified $\mathrm{CaCl}_{2} / \mathrm{CaO}$ in the crucible. The dark gray product remaining in the crucible was washed again with distilled water, acetic acid, and ethanol to remove residual impurities. Several small product samples were also collected by filtration from the washing water. Finally, the obtained product was dried and stored in a vacuum desiccator.

The nanomorphology of the product was examined by field emission scanning electron microscopy (FE-SEM, JSM-6500F, JEOL, Japan) and transmission electron microscopy (TEM, JEM-2010F, JEOL). The phase composition of the product was identified by energy dispersive X-ray spectroscopy (EDS, JEM-2010F, JEOL).

\section{Results and Discussion}

Figure 1a shows the changes in the current, I, with the electrolysis time, $\mathrm{t}$, at a constant applied voltage of $3.1 \mathrm{~V}$ and a temperature of $1173 \mathrm{~K}$ in molten $\mathrm{CaCl}_{2} / \mathrm{CaO}$ a) without and $\mathrm{b}$ ) with iron additives. During electrolysis without iron additives, the current was measured to be approximately $1.60 \mathrm{~A}$ after the initial transient period of electrolysis, and then, it gradually decreased with increasing electrolysis time, demonstrating a value of approximately $1.25 \mathrm{~A}$ for long-term electrolysis of $8 \mathrm{ks}$. The shape of the current-time transient with iron additives was very similar to that without iron additives, and there are no significant differences between the electrolysis with and without iron additives. Figure $1 \mathrm{~b}$ shows the surface appearance of the solidified $\mathrm{CaCl}_{2} / \mathrm{CaO}$ without iron additives in the $\mathrm{MgO}$ crucible after constant voltage electrolysis for $8 \mathrm{ks}$. It was clearly observed that the entire surface of the solidified salt was covered with much dark gray product. The cross-sectional fracture image of this solidified salt is shown in 

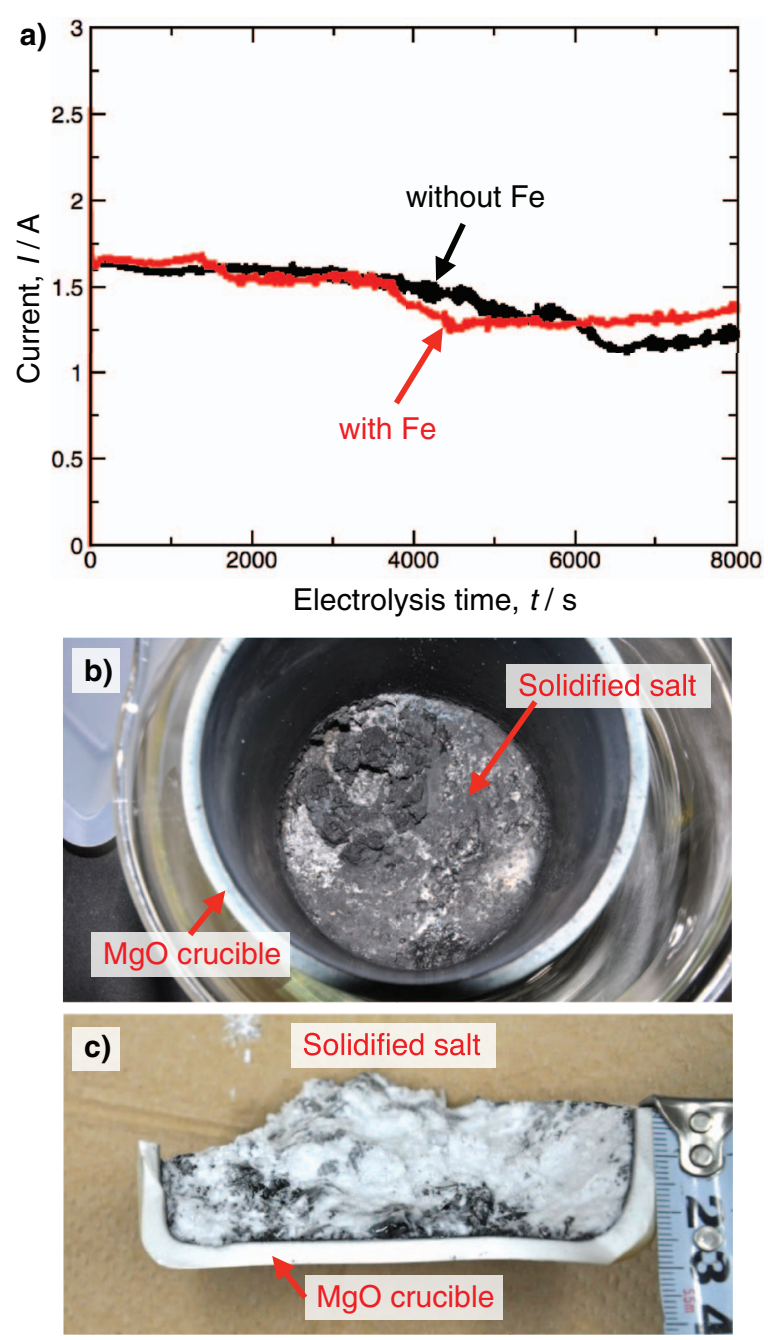

Figure 1. a) Changes in the current, I, with the electrolysis time, t, during constant voltage electrolysis in molten $\mathrm{CaCl}_{2} / \mathrm{CaO}$ at $1173 \mathrm{~K}$ with and without iron additives. Two graphite rods were used as the anode and cathode. b) Appearance of the solidified $\mathrm{CaCl}_{2} / \mathrm{CaO}$ salt in a $\mathrm{MgO}$ crucible after electrolysis without iron additives. c) Fracture cross-sectional image of the $\mathrm{CaCl}_{2} / \mathrm{CaO}$ solidified salt.

Figure 1c. The bulk inside of the solidified salt also contained the dark gray product, although the product was widely distributed at the interface between the $\mathrm{MgO}$ crucible and solidified salt. After electrolysis with iron additives, a similar dark gray product was also formed in the solidified salt. Conversely, when the graphite electrode was immersed in molten salt at $1173 \mathrm{~K}$ without an applied voltage, the dark gray product could not be obtained.

During electrolysis in molten $\mathrm{CaCl}_{2} / \mathrm{CaO}$ at $1173 \mathrm{~K}$, the following electrochemical reactions occur at the graphite anode and cathode: ${ }^{18}$

$$
\begin{gathered}
\mathrm{C}+2 \mathrm{O}^{2-} \rightarrow \mathrm{CO}_{2}+4 \mathrm{e}^{-} \text {(anodic reaction) } \\
\mathrm{Ca}^{2+}+2 \mathrm{e}^{-} \rightarrow \mathrm{Ca} \text { (cathodic reaction) }
\end{gathered}
$$

Therefore, $\mathrm{CO}_{2}$ gas was generated from the anode, and liquid metallic calcium was also formed at the cathode. The liquid calcium metal can be easily dissolved in molten $\mathrm{CaCl}_{2}$ due to its high solubility of $3.9 \mathrm{~mol} \%$ in molten $\mathrm{CaCl}_{2}$ at $1173 \mathrm{~K} .^{6,9}$ Although the $\mathrm{CO}_{2}$ gas generated from the anode was discharged through the outlet with argon carrier gas, a fraction of the $\mathrm{CO}_{2}$ gas will react with dissolved metallic calcium in molten $\mathrm{CaCl}_{2}$ by the following electrochemical reaction: ${ }^{11}$

$$
\mathrm{CO}_{2}+\mathrm{Ca} \rightarrow \mathrm{C}+\mathrm{Ca}^{2+}+2 \mathrm{O}^{2-} \text { in molten } \mathrm{CaCl}_{2}
$$
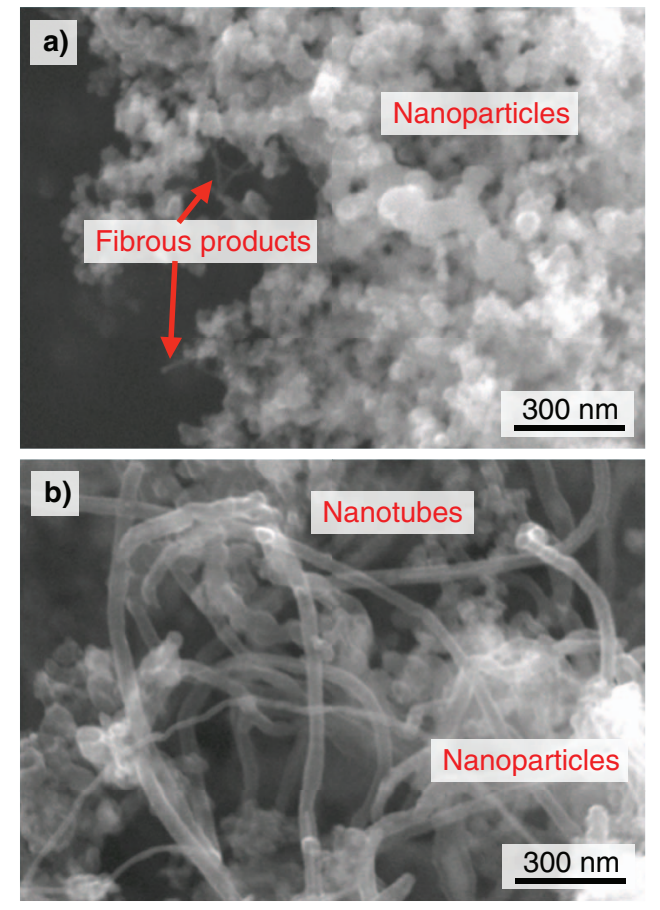

Figure 2. SEM images of the dark gray products formed via calciothermic reduction a) with and $b$ ) without iron additives.

Therefore, $\mathrm{CO}_{2}$ gas was reduced again to carbon by dissolved metallic calcium during electrolysis, and reduced carbon products were deposited in the solidified $\mathrm{CaCl}_{2} / \mathrm{CaO}$ after electrolysis, as described in Figs. $1 \mathrm{~b}$ and 1c. The reason why the current decreased gradually with increasing electrolysis time may be due to $\mathrm{O}^{2-}$ concentration decreased during electrolysis because a fraction of the $\mathrm{CO}_{2}$ gas was discharged through the outlet. The morphologies of the reduced carbon products obtained by the two different electrolysis experiments were examined by FE-SEM.

Figure 2 shows SEM images of the typical reduced products obtained via $\mathrm{CaCl}_{2} / \mathrm{CaO}$ electrolysis a) without and b) with iron additives. An aggregate consisting of numerous fine nanoparticles measuring several tens of nanometers was formed by electrolysis without iron additives (Fig. 2a). In addition, a small amount of fibrous nanostructures was also observed in the nanoparticle aggregate. In contrast, a similar fine nanoparticle aggregate and remarkable characteristic nanotubes measuring several tens of nanometers in diameter were formed by electrolysis with iron additives (Fig. 2b). Comparing these SEM images, the nanomorphologies of the reduced carbon products obtained via electrolysis in the presence or absence of iron additives were greatly different. Therefore, the detailed nanomorphologies of these carbon products were examined by high-resolution TEM (HRTEM).

Figures $3 \mathrm{a}$ shows a TEM image of the fine nanoparticle aggregate obtained via $\mathrm{CaCl}_{2} / \mathrm{CaO}$ electrolysis without iron additives. Similar to Fig. 2a, it is observed that numerous fine nanoparticles measuring several tens of nanometers aggregated. From the EDS measurements, these nanoparticles consisted of carbon containing small amounts of calcium and chlorine, which originated from the molten $\mathrm{CaCl}_{2} / \mathrm{CaO}$. These elemental impurities may be incorporated at the interface between each carbon nanoparticle reduced with calcium reductant during the agglutination in molten salt. Figure $3 \mathrm{~b}$ shows a HRTEM image of these carbon nanoparticles, and it can be seen that the nanoparticles were well crystallized and consisted of a large number of spherical graphite layers. The appearance of these carbon nanoparticles was very similar to onion-like carbons (OLCs) obtained by several synthetic techniques. ${ }^{35,36}$

Figure $3 \mathrm{c}$ shows a TEM image of fibrous nanostructures obtained via electrolysis without iron additives, as described in Fig. 2a. The 


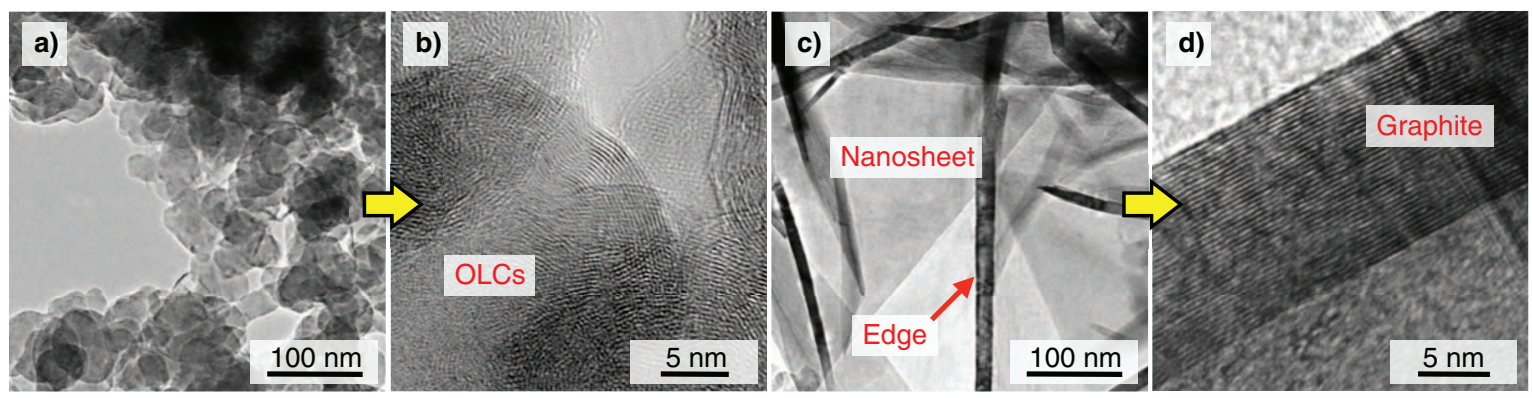

Figure 3. TEM images of the carbon products obtained via the calciothermic reduction of $\mathrm{CO}_{2}$ in molten $\mathrm{CaCl}_{2} / \mathrm{CaO}$ without iron additives at $1173 \mathrm{~K}$ : a) and b) onion-like carbons (OLCs), c) and d) thin graphite sheets.
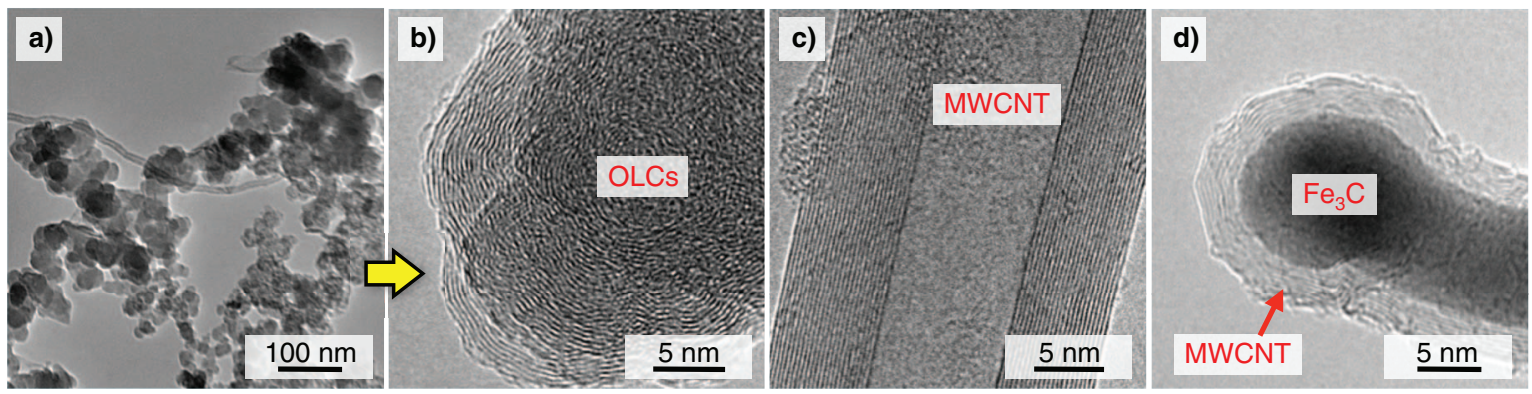

Figure 4. TEM images of the carbon products obtained via the calciothermic reduction of $\mathrm{CO}_{2}$ in molten $\mathrm{CaCl}_{2} / \mathrm{CaO}$ with iron additives at $1173 \mathrm{~K}$ : a) overall appearance, b) OLCs, c) multi-walled carbon nanotube (MWCNT), and d) $\mathrm{MWCNT} / \mathrm{Fe}_{3} \mathrm{C}$ nanocomposite.

fibrous nanostructures measuring approximately $10 \mathrm{~nm}$ in width were observed on several thin sheet-like products. When the fibrous nanostructures were closely observed, it was found that the nanostructures corresponded to the edge of thin sheet-like products. From the EDS measurements, these nanostructures consisted of pure carbon without elemental impurities. As these carbon nanostructures were observed by HRTEM (Fig. 3d), the nanostructures were a thin graphite sheet composed of approximately 40 graphite layers measuring $14 \mathrm{~nm}$ in thickness. In summary, the calciothermic reduction of $\mathrm{CO}_{2}$ via electrolysis in molten $\mathrm{CaCl}_{2} / \mathrm{CaO}$ without iron additives resulted in the formation of OLCs and thin graphite sheets, but CNTs were not observed in the products.

Figure 4a shows a typical TEM image of the reduced products obtained via $\mathrm{CaCl}_{2} / \mathrm{CaO}$ electrolysis with iron additives. Similar to Fig. 2b, numerous fine nanoparticles and a tubular nanostructure can be observed in the products. A HRTEM image of the fine nanoparticles is shown in Fig. 4b, and OLCs with a large number of spherical graphite layers were observed. Similar to without iron additives (Fig. $3 b$ ), the OLCs contained small amounts of calcium and chlorine impurities. On the other hand, a HRTEM image of a tubular nanostructure is shown in Fig. 4c, and multi-walled CNTs (MWCNTs) possessing approximately 25 graphite layers were observed. From the HRTEM observations at different positions, various MWCNTs with different numbers of graphite layers were formed by electrolysis with iron additives. Interestingly, these MWCNTs partially included cementite $\left(\mathrm{Fe}_{3} \mathrm{C}\right)$ in their inside, as shown in Fig. 4d. Such $\mathrm{Fe}_{3} \mathrm{C}$ intermetallic compounds were deposited at several places on the insides of the MWCNTs. In summary, the calciothermic reduction of $\mathrm{CO}_{2}$ via electrolysis in molten $\mathrm{CaCl}_{2} / \mathrm{CaO}$ with iron additives resulted in the formation of OLCs and MWCNT/Fe ${ }_{3} \mathrm{C}$ nanocomposites. A graphite sheet, as observed in Fig. 3c, was not formed by electrolysis with iron additives.

During electrolysis with iron additives, the carbon products reduced by the calcium reductant and metallic iron additives coexisted in the molten $\mathrm{CaCl}_{2} / \mathrm{CaO}$. Therefore, intermetallic compounds of $\mathrm{Fe}_{3} \mathrm{C}$ were easily formed in the molten salt at high temperature. These $\mathrm{Fe}_{3} \mathrm{C}$ compounds induce the formation of MWCNTs during the reduction of $\mathrm{CO}_{2}$. Consequently, many MWCNTs were formed in the prod- ucts obtained by electrolysis with iron additives. In fact, fabrication of $\mathrm{MWCNT} / \mathrm{Fe}_{3} \mathrm{C}$ nanocomposites via different synthetic techniques has been reported by several research groups. ${ }^{37,38}$ Such $\mathrm{MWCNT} / \mathrm{Fe}_{3} \mathrm{C}$ nanocomposites may be used as a carbon nanotube material with magnetic properties. Selective removal and attraction of $\mathrm{MWCNT} / \mathrm{Fe}_{3} \mathrm{C}$ nanocomposites may be achieved by magnetic field. Although this technique requires the consumption of a large amount of electricity for the generation of the calcium reductant at high temperature, the calciothermic reduction allows the simultaneous decomposition of atmospheric $\mathrm{CO}_{2}$ and the subsequent fabrication of $\mathrm{MWCNT} / \mathrm{Fe}_{3} \mathrm{C}$ nanocomposites, thus accomplishing two things with one technique. For future industrial applications, the electricity consumption for electrolysis must be supplied from renewable energy such as solar energy. In addition, the optimum conditions for the large-scale synthesis of well-ordered $\mathrm{MWCNT} / \mathrm{Fe}_{3} \mathrm{C}$ nanocomposites via the calciothermic reduction of $\mathrm{CO}_{2}$ should be further investigated.

\section{Conclusions}

We demonstrated a novel synthesis of $\mathrm{MWCNT} / \mathrm{Fe}_{3} \mathrm{C}$ nanocomposites via the calciothermic reduction of $\mathrm{CO}_{2}$ in molten $\mathrm{CaCl}_{2} / \mathrm{CaO}$ with iron additives at high temperature. The calciothermic reduction of $\mathrm{CO}_{2}$ without iron additives results in the formation of a mixture of OLCs and graphite sheets. In contrast, OLCs and MWCNT/Fe ${ }_{3} \mathrm{C}$ nanocomposites were successfully fabricated via calciothermic reduction with iron additives due to the catalysis of $\mathrm{Fe}_{3} \mathrm{C}$ intermetallic compound formed by the chemical reaction of reduced carbon and iron additives.

\section{Acknowledgments}

This work was financially supported by the Japan Science and Technology Agency (JST) "ALCA". This research was also supported by the "Nanotechnology Platform" Program of the MEXT, Japan. Finally, we would like to dedicate this article to Ryoma Ishida, one of the authors, who passed away by way of an accident during the writing of the manuscript. 


\section{References}

1. K. Ono and R. O. Suzuki, JOM, 54, 59 (2002).

2. K. Ono, Mater. Trans., 45, 1660 (2004).

3. K. T. Jacob and S. Gupta, JOM, 61, 56 (2009).

4. R. O. Suzuki and S. Inoue, Metall. Mater. Trans. B, 34, 277 (2003).

5. R. O. Suzuki, K. Ono, and K. Teranuma, Metall. Mater. Trans. B, 34, 287 (2003).

6. R. O. Suzuki, J. Phys. Chem. Solids, 66, 461 (2005).

7. H. Zheng, H. Ito, and T. H. Okabe, Mater. Trans., 48, 2244 (2007).

8. B. Xu, B. Yang, J. Jia, D. Liu, H. Xiong, and Y. Deng, J. Alloys Comp., 576, 208 (2013).

9. T. Kikuchi, M. Yoshida, S. Matsuura, S. Natsui, E. Tsuji, H. Habazaki, and R. O. Suzuki, J. Phys. Chem. Solids, 75, 1041 (2014).

10. A. M. Abdelkader and E. El-Kashif, ISIJ Int., 47, 25 (2007).

11. A. M. Abdelkader, A. Daher, R. A. Abdelkareem, and E. El-Kashif, Metall. Mater Trans. B, 38, 35 (2007).

12. A. M. Abdelkader and A. Daher, J. Alloys Comp., 459, 571 (2009).

13. T. H. Okabe, I. Park, K. T. Jacob, and Y. Waseda, J. Alloys Comp., 288, 200 (1999).

14. M. Baba, Y. Ono, and R. O. Suzuki, J. Phys. Chem. Solids, 66, 466 (2005).

15. X. Y. Yan and D. J. Fray, J. Electrochem. Soc., 152, E308 (2005).

16. R. O. Suzuki, M. Baba, Y. Ono, and K. Yamamoto, J. Alloys Comp., 389, 310 (2005).

17. K. T. Jacob and A. Rajput, J. Alloys Comp., 620, 256 (2015).

18. R. F. Descallar-Arriesgado, N. Kobayashi, T. Kikuchi, and R. O Suzuki, Electrochim Acta, 56, 8422 (2011).

19. Y. Sakamura, M. Kurata, and T. Inoue, J. Electrochem. Soc., 153, D31 (2006)

20. T. H. Okabe, K. Fujiwara, T. Oishi, and K. Ono, Metall. Mater. Trans. B, 23, 415 (1992).

21. M. Ohtsuka, D. Y. Kim, and K. Itagaki, J. Alloys Comp., 230, 46 (1995).
22. A. Verma, R. K. Sidhu, S. Mahajan, and O. P. Pandey, J. Mater. Sci. Lett., 15, 2088 (1996).

23. S. Osaki, H. Sakai, and R. O. Suzuki, J. Electrochem. Soc., 157, E117 (2010).

24. B. S. Moorhouse, T. Reddyhoff, M. Ward-Close, M. P. Ryan, and B. A. Shollock, Surf. Coat. Technol., 221, 214 (2013).

25. T. Kikuchi, M. Yoshida, Y. Taguchi, H. Habazaki, and R. O. Suzuki, J. Alloys Comp., 586, 148 (2014).

26. M. Panigrahi, A. Iizuka, E. Shibata, and T. Nakamura, J. Alloys Comp., 550, 545 (2013).

27. M. Panigrahi, E. Shibata, A. Iizuka, and T. Nakamura, Electrochim. Acta, 93, 143 (2013).

28. G. Z. Chen, D. J. Fray, and T. W. Farthing, Nature, 407, 361 (2000).

29. G. Z. Chen and D. J. Fray, J. Electrochem. Soc., 149, E455 (2002).

30. T. M. Wigley, R. Richels, and J. A. Edmonds, Nature, 379, 240 (1996).

31. K. Sayama and H. Arakawa, J. Phys. Chem., 97, 531 (1993).

32. K. Hashimoto, M. Yamasaki, K. Fujimura, T. Matsui, K. Izumiya, M. Komori, A. A. El-Moneim, E. Akiyama, H. Habazaki, N. Kumagai, A. Kawashima, and K. Asami, Mater. Sci. Eng. A, 267, 200 (1999).

33. K. Otake, H. Kinoshita, T. Kikuchi, and R. O. Suzuki, Electrochim. Acta, 100, 293 (2013).

34. T. Wakamatsu, T. Uchiyama, S. Natsui, T. Kikuchi, and R. O. Suzuki, Fluid Phase Equilibria, 385, 48 (2015).

35. N. Keller, N. I. Maksimova, V. V. Roddatis, M. Schur, G. Mestl, Y. V. Butenko, V. L. Kuznetsov, and R. Schlögl, Angew. Chem. Int. Ed., 41, 1885 (2002).

36. J. Zheng, T. C. Ekström, S. K. Gordeev, and M. Jacob, J. Mater. Chem., 10, 1039 (2000).

37. Q. Su, G. Zhong, J. Li, G. Du, and B. Xu, Appl. Phys. A, 106, 59 (2012).

38. P. Xu, X. J. Han, X. R. Liu, B. Zhang, C. Wang, and X. H. Wang, Mater. Chem. Phys., 114, 556 (2009). 